\title{
Produção e fisiologia de plantas de cajueiro anão precoce sob condições de sequeiro e irrigado
}

\author{
Aiala V. Amorim ${ }^{1}$, Enéas G omes-Filho², Marlos A. Bezerra ${ }^{3}$, \\ José T. Prisco ${ }^{2} \&$ Claudivan F. de Lacerda ${ }^{5}$
}

\begin{abstract}
RESU MO
A exploração do cajueiro sob condições de irrigação tem-se mostrado bastante promissora, especialmente no estado do Ceará, porém a resposta dessa cultura ao regime hídrico depende do genótipo. O bjetivouse, com este trabalho, comparar respostas fisiológicas e bioquímicas (teores de solutos orgânicos e inorgânicos e trocas gasosas), tal como a produtividade de plantas de cajueiro anão precoce (Anacardium occidentale L.) sob dois regimes hídricos (sequeiro e irrigado). 0 experimento foi conduzido no Campo Experimental da Embrapa Agroindústria Tropical, em Pacajus CE, no período de agosto de 2006 a janeiro de 2007. As plantas foram submetidas a dois tratamentos: um sem irrigação e outro com água de poço com condutividade elétrica (CEa) de $0,5 \mathrm{dS} \mathrm{m}^{-1}$. As respostas fisiológicas foram avaliadas mensalmente e os dados de produção foram obtidos no período de novembro a janeiro. Os teores foliares de $\mathrm{N}$ aminossolúveis e prolina foram mais elevados nas plantas cultivadas em condições de sequeiro do que naquelas irrigadas, porém não houve diferença significativa entre os tratamentos para as trocas gasosas, teores de carboidratos solúveis, $\mathrm{K}^{+}, \mathrm{N} \mathrm{a}^{+}$e $\mathrm{Cl}^{-}$. Entretanto, com exceção da fotossíntese, todas as variáveis estudadas apresentaram alterações com as épocas de coleta. A pesar das alterações em al gumas variáveis ao longo do experimento, a produtividade das plantas não foi afetada pelo estresse hídrico.
\end{abstract}

Palavras-chave: Anacardium occidentale, estresse hídrico, produtividade, trocas gasosas

\section{Production and physiology of dwarf cashew plants under rainfed and irrigated conditions}

\begin{abstract}
The exploitation of cashew under irrigated conditions has been very promising, especially in the state of Ceará, however, the response of this crop to the water regime depends on the genotype. This work attempts to compare the physiological and biochemical responses (content of organic and inorganic solutes and gas exchange) and yield of precocious dwarf cashew (Anacardium occidentale L) plants under two water regimes (irrigated and rainfed). The experiment was conducted at the experimental field of Embrapa Agroindústria Tropical, in Pacajus, Ceará, from August 2006 to January 2007. The plants were subjected to two treatments: without irrigation and another irrigated with water with electrical conductivity of $0.5 \mathrm{dS} \mathrm{m}^{-1}$. The physiological responses were assessed monthly and the production data were obtained from November to January. The levels of $\mathrm{N}$-aminosoluble and proline in the leaves of plants grow $\mathrm{n}$ under dry farming conditions were higher than in irrigated, but no significant difference was found betw een treatments for gas exchange, soluble carbohydrates, $\mathrm{K}^{+}, \mathrm{N} \mathrm{a}^{+}$and $\mathrm{Cl}^{-}$. However, except for photosynthesis, all the variables showed changes in collection times. Despite changes in some variables during the experiment, the yield of plants was not affected by water stress.
\end{abstract}

Key words: Anacardium occidentale, water stress, productivity, gas exchange

${ }^{1}$ DF/UFC, Av. Mister Hull s/n, Campus do Pici, CEP 60021-970, Fortaleza, CE. Fone: (85) 3366-9405. E-mail: aialaamorim@hotmail.com 2 DBBM/UFC, Fone: (85) 3366-9405.E-mail: egomesf@ufc.br; jtprisco@superig.com.br

${ }^{3}$ Embrapa CN PAT, Rua Dr. Sara Mesquita 2270, Planalto do Pici, CEP 60511-110, Fortaleza, CE. Fone: (85) 3391-7100. E-mail: marlos@cnpat.embrapa.br

${ }^{4}$ DEN A/U FC, Fone: (85) 3366-9721. E-mail: cfeitosa@ufc.br 


\section{INTRODUÇÃO}

O cajueiro é considerado uma das mais importantes espécies cultivadas das regiões tropicais ocupando, no mundo, uma área estimada de 3,39 milhões de hectares, tendo como principais produtos de expressão econômica a amêndoa comestível e o líquido da casca da castanha (Oliveira, 2008). A produção mundial de castanha é de cerca de 3,7 milhões de toneladas destacando-se, como principais produtores: Vietnã, Índia, Nigéria, Costa do Marfim e Brasil (FAO, 2009). No Brasil, a cajucultura tem grande importância socioeconômica, mobilizando cerca de 280 mil pessoas, com uma área cultivada de 740 mil hectares gerando, de forma expressiva, divisas externas (Oliveira, 2008; Carneiro et al. 2002). A Região Nordeste se destaca ao responder por cerca de $100 \%$ da produção interna, em que o estado do Ceará se sobressai maior produtor, perfazendo cerca de 39\% dessa produção (IBGE, 2008).

Embora tenha havido um acréscimo substancial da área cultivada com cajueiro nos últimos anos, a produção e a produtividade brasileira de castanha de caju se vêm mantendo em níveis baixos, com média, em 2007, em torno de 190 kg de castanha por hectare (Oliveira, 2008). Esta situação é reflexo principalmente da deficiente infraestrutura de produção (oferta de mudas de qualidade, baixa adoção de tecnologia de cultivo, baixa adoção de tecnologia de colheita e pós-colheita) na maioria das áreas cultivadas, das secas cíclicas nas principais regiões produtoras, da ocorrência de pragas e doenças em todos os subperíodos do desenvolvimento e da propagação sexuada utilizada para a formação dos pomares (Oliveira, 2008). Para se ter uma idéia disso, durante a década de 70 a produtividade cearense era de $550 \mathrm{~kg}_{\text {castanha }} \mathrm{ha}^{-1} \mathrm{ano}^{-1}$ e caiu para $400 \mathrm{~kg} \mathrm{ha}^{-1} \mathrm{ano}^{-1}$ na década de 80 , chegando a atingir 217 $\mathrm{kg} \mathrm{ha}^{-1} \mathrm{ano}^{-1}$ no período de 1999 a 2002 (Oliveira et al., 2003).

Entretanto, nos últimos anos a propagação vegetativa do cajueiro e a prática de irrigação se vêm tornando relevantes para o estabelecimento de novos pomares com potencial produtivo. A exploração dessa cultura sob condições de irrigação, tem-se mostrado bastante promissora, sobremaneira no estado do Ceará, onde foram implantados cerca de 1.500 ha de pomares irrigados (Oliveira et al., 2003). Ressalta-se, porém, que a resposta do cajueiro anão precoce ao regime hídrico depende do seu genótipo: por exemplo, Oliveira (2002) verificou, estudando a influência da irrigação na produção de castanhas e de pedúnculos em três genótipos de cajueiro anão precoce (CP-09; CP-76 e CP-1001), que apenas o genótipo CP - 1001 apresentou respostas positivas quando irrigado.

A deficiência hídrica, além de reduzir a produção também afeta os processos bioquímicos e fisiológicos das plantas (Shinozaki \& Yamaguchi-Shinozaki, 2007). Nesse tipo de estresse a fotossíntese é geralmente reduzida, o que leva a uma diminuição na produção e no consumo de fotoassimilados, alterando a partição de carboidratos nas folhas e na planta, como um todo (Lawlor \& Cornic, 2002). Por outro lado, os teores de diversos solutos podem aumentar em resposta à deficiência de água. Por exemplo, aumentos nos teores de prolina e $\mathrm{N}$-aminossolúveis foram detectados por alguns autores que trabalharam com deficiência hídrica em diversas espécies de plantas (Bray et al., 2000; Nogueira et al., 2001).
Em virtude do Nordeste brasileiro apresentar um índice pluviométrico irregular, torna-se relevante estudar a resposta de uma cultura extremamente importante para essa região. Objetivou-se, portanto, com este trabalho, avaliar o efeito da irrigação na produção de castanha, nas trocas gasosas e no acúmulo de solutos orgânicos e inorgânicos de plantas adultas de cajueiro anão precoce.

\section{Material e MÉTODOS}

O experimento foi conduzido no Campo Experimental de Pacajus, pertencente à Embrapa Agroindústria Tropical $\left(4^{\circ} 10^{\prime}\right.$ $\mathrm{S} ; 38^{\circ} 27^{\prime} \mathrm{W}, 60 \mathrm{~m}$ ), no período de agosto de 2006 a janeiro de 2007. O pomar de cajueiro anão precoce (Anacardium occidentale L.) foi formado em 1997, a partir de mudas enxertadas do clone CCP-76 sobre o clone CCP-06, e em 2003 o mesmo foi submetido a poda drástica, retirando-se toda a copa e se deixando apenas parte do caule (aproximadamente $50 \mathrm{~cm}$ de altura). O solo do local tem predominância de neossolo quartzarênico com classe textural areia e densidade de 1,46 $\mathrm{g} \mathrm{kg}^{-1}$. As características químicas do mesmo, medidas na camada de 0 a $20 \mathrm{~cm}$, estão descritas na Tabela 1.

Tabela 1. A tributos químicos do solo na camada de 0 a $0,20 \mathrm{~m}$ de profundidade, na área experimental, antes da aplicação dos tratamentos

\begin{tabular}{lc}
\hline Atributos & Valores \\
$\mathrm{pH}$ & 5,40 \\
$\mathrm{CE}\left(\mathrm{dS} \mathrm{m}^{-1}\right)$ & 0,33 \\
$\mathrm{Ca}\left(\mathrm{mmol}_{\mathrm{c}} \mathrm{kg}^{-1}\right)$ & 6,20 \\
$\mathrm{Mg}\left(\mathrm{mmol}_{\mathrm{c}} \mathrm{kg}^{-1}\right)$ & 2,70 \\
$\mathrm{~K}\left(\mathrm{mmol}_{\mathrm{c}} \mathrm{kg}^{-1}\right)$ & 1,50 \\
$\mathrm{Na}\left(\mathrm{mmol}_{\mathrm{c}} \mathrm{kg}^{-1}\right)$ & 0,70 \\
$\mathrm{Al}\left(\mathrm{mmol}_{\mathrm{c}} \mathrm{kg}^{-1}\right)$ & 0,80 \\
$\mathrm{H}+\mathrm{Al}\left(\mathrm{mmol}_{\mathrm{c}} \mathrm{kg}^{-1}\right)$ & 19,00 \\
$\mathrm{C} . \mathrm{T} . \mathrm{C}\left(\mathrm{mmol}_{\mathrm{c}} \mathrm{kg}^{-1}\right)$ & 30,10 \\
$\mathrm{P} \mathrm{O}_{5}\left(\mathrm{mg} \mathrm{kg}^{-1}\right)$ & 1,40 \\
$\mathrm{Cu}\left(\mathrm{mg} \mathrm{kg}^{-1}\right)$ & 0,20 \\
$\mathrm{Fe}\left(\mathrm{mg} \mathrm{kg}^{-1}\right)$ & 10,70 \\
$\mathrm{Mn}\left(\mathrm{mg} \mathrm{kg}^{-1}\right)$ & 9,60 \\
$\mathrm{Zn}\left(\mathrm{mg} \mathrm{kg}^{-1}\right)$ & 0,90 \\
\hline
\end{tabular}

Utilizou-se o delineamento experimental de blocos inteiramente casualizados em parcelas subdivididas, sendo as parcelas constituídas pelos regimes hídricos (sequeiro e irrigado) e as subparcelas pelas épocas de coleta (meses de agosto, setembro, outubro, novembro e dezembro). O espaçamento utilizado foi $8 \mathrm{~m}$ entre linhas e $6 \mathrm{~m}$ entre plantas, com quatro repetições de quatro plantas por parcela, em uma área de aproximadamente 0,4 ha.

As plantas foram fertilizadas de acordo com o sistema preconizado pela Embrapa Agroindústria Tropical (Oliveira, 2002). A precipitação pluviométrica média do local foi de 3,8 ; 4,$0 ; 0,0 ; 9,0$ e $0,0 \mathrm{~mm}$, respectivamente, nos meses de agosto, setembro, outubro, novembro e dezembro sendo a média de umidade relativa do ar $71,6 \%$ e a temperatura média de $26,3^{\circ} \mathrm{C}$, considerando-se todos os meses.

A metade das plantas recebeu irrigação com água de poço artesiano $\left(\mathrm{CEa}=0,5 \mathrm{dS} \mathrm{m}^{1}\right)$ e a outra metade ficou sem irrigação 
(sequeiro). O método de irrigação usado foi o de microaspersão, utilizando-se cerca de 100 L de água aplicados em cada planta três vezes por semana, seguindo-se recomendações de irrigação para cajueiro anão precoce, no litoral do Ceará (Crisóstomo et al., 2001).

\section{Trocas gasosas e potencial osmótico}

A taxa de assimilação líquida de carbono (A), a taxa de transpiração (E) e a condutância estomática $\left(g_{s}\right)$ foram medidas uma vez por mês, de agosto a dezembro, em folhas completamente expandidas, nos quatro pontos cardeais do terço médio externo da copa, com o auxílio de um analisador de gás no infravermelho (IRGA, LCi System, ADC, Hoddesdom). As medições foram realizadas sempre entre 9 e $12 \mathrm{~h}$ do dia, posterior à irrigação. O período amostrado abrange os estádios de floração (agosto e setembro) e de frutificação (outubro a dezembro) das plantas. Os dados de temperatura, umidade relativa do ar e déficit de pressão de vapor no momento das medições, se encontram na Tabela 2.

Tabela 2. Dados climáticos da Estação Experimental de Pacajus, CE, no momento da medição das trocas gasosas e da coleta de folhas

\begin{tabular}{cccc}
\hline Data & $\begin{array}{c}\text { Temperatura } \\
\left({ }^{\circ} \mathbf{C}\right)\end{array}$ & $\begin{array}{c}\text { Umidade } \\
\text { relativa(\%) }\end{array}$ & $\begin{array}{c}\text { DPV } \\
(\mathbf{k P a})\end{array}$ \\
23.08 .06 & 27,3 & 65,6 & 1,24 \\
20.09 .06 & 28,3 & 60,8 & 1,50 \\
25.10 .06 & 29,1 & 57,6 & 1,70 \\
21.11 .06 & 27,5 & 70,4 & 1,50 \\
19.12 .06 & 29,4 & 59,2 & 1,67 \\
\hline
\end{tabular}

Fonte: Funceme (2007)

O potencial osmótico $\left(\mathrm{Y}_{\mathrm{S}}\right)$ das plantas foi determinado a partir do suco celular obtido em temperatura ambiente, após centrifugação do macerado das folhas em almofariz. Do líquido obtido utilizou-se uma alíquota de $100 \mu \mathrm{L}$ para determinação do potencial osmótico em um osmômetro (Osmometer Automatic, Type 13/13DR-Autocal, Advanced Instruments Inc., Needham Heights, Massachusetts, EEUU), sendo o valor expresso em $\mathrm{MPa}$.

\section{Solutos orgânicos e inorgânicos}

Mensalmente foram realizadas coletas de folhas completamente expandidas, nos quatro pontos cardeais do terço médio externo da copa; após a coleta as folhas foram imediatamente congeladas em nitrogênio líquido $\left(-196^{\circ} \mathrm{C}\right)$ e em seguida transportadas em ambiente refrigerado até o laboratório, onde foram liofilizadas, maceradas e o pó resultante armazenado a $5^{\circ} \mathrm{C}$, para posterior análise de solutos orgânicos e inorgânicos.

Os extratos para determinação de solutos foram obtidos a partir de $100 \mathrm{mg}$ do pó liofilizado das folhas, os quais foram homogeneizados com $10 \mathrm{~mL}$ de água desionizada durante 30 min, sob agitação constante; em seguida, o homogenato foi centrifugado a $3000 \mathrm{x}$ g por $10 \mathrm{~min}$, sendo o sobrenadante filtrado e armazenado a $-25^{\circ} \mathrm{C}$. A determinação de prolina livre foi realizada de acordo com Bates et al. (1973). Os teores de Naminossolúveis foram determinados de conformidade com
Yemm \& Cocking (1955) e os de carboidratos solúveis foram determinados segundo Dubois et al. (1956). Os teores de sódio e potássio foram determinados por fotometria de chama e os de cloreto através de leituras de absorbância em 460 nm (Gaines et al., 1984). Os teores de solutos orgânicos e inorgânicos foram expressos em $\mu \mathrm{mol} \mathrm{g}^{-1}$ de matéria seca (MS).

\section{Produção}

Para avaliação da produção e da produtividade das castanhas foram realizadas coletas periódicas dos frutos, durante todo o período de produção. Após cada coleta as castanhas foram separadas do pedúnculo e postas para secar, até que atingissem $15 \%$ de umidade, quando então foram pesadas. O somatório dessas pesagens foi utilizado para expressar a produção em castanha planta ${ }^{-1}$ e a produtividade em kg ha ${ }^{-1}$. Para essas variáveis não foi utilizado o esquema em fatorial aplicando-se apenas o teste de médias, após a análise de variância.

Os dados obtidos foram submetidos à análise de variância pelo teste $\mathrm{F}$ a nível de 5\% de probabilidade, através do software "Assistat 7.5 Beta" (Silva \& Azevedo, 2009).

\section{RESULTADOS E DISCUSSÃO}

\section{Trocas gasosas e potencial osmótico}

As variáveis relacionadas a trocas gasosas não diferiram estatisticamente entre os regimes hídricos (Tabela 3 e Figura 1); entretanto, quando foram levadas em consideração as épocas das determinações observou-se que, enquanto a fotossíntese líquida (A) não sofreu alteração significativa, as taxas de transpiração $(\mathrm{E})$ e condutância estomática $\left(\mathrm{g}_{\mathrm{s}}\right)$ foram estatisticamente diferentes; além disso, todas as variáveis de troca gasosa avaliadas não sofreram alterações significativas na interação tratamento versus época (Tabela 3).

Tabela 3. Resumo da análise de variância para fotossíntese líquida (A), transpiração (E) e condutância estomática $\left(g_{s}\right)$ de folhas de cajueiro anão precoce cultivado sob condições de sequeiro e de irrigação

\begin{tabular}{lccc}
\hline \multirow{2}{*}{ Fonte de variação } & \multicolumn{3}{c}{ Quadrado médio } \\
\cline { 2 - 4 } & $\mathbf{A}$ & $\mathbf{E}$ & $\mathbf{g}_{\mathrm{s}}$ \\
Regimes Hídricos (A) & $2,54^{\text {ns }}$ & $0,00054^{\text {ns }}$ & $0,37^{\text {ns }}$ \\
Resíduo (A) & 4,87 & 0,731 & 0,049 \\
Época (B) & $1,29^{\text {ns }}$ & $5,64^{*}$ & $3,005^{* *}$ \\
Int. (A x B) & $6,00^{\text {ns }}$ & $0,55^{\text {ns }}$ & $0,31^{\text {ns }}$ \\
Resíduo (B) & 3,14 & 1,40 & 0,513 \\
CV\% (A) & 14,53 & 17,02 & 6,35 \\
CV\% (B) & 11,67 & 23,56 & 20,41 \\
\hline
\end{tabular}

$\left(^{*}\right)$ Significativo e ${ }^{(\text {ns })}$ não significativo $(P \leq 0,05)$

Os valores de A não apresentaram diferenças estatísticas significativas para regimes hídricos nem para épocas e interação, com um valor médio de 15,2 $\mathrm{mmol} \mathrm{m}^{-2} \mathrm{~s}^{-1}$ (Figura 1A). Valores dessa ordem de grandeza para a fotossíntese líquida também foram observados por Souza et al. (2005) em plantas jovens de cajueiro anão precoce sob condições de temperatura entre 25 e $30^{\circ} \mathrm{C}$. Tampouco se observaram efeitos dos regimes 
A.

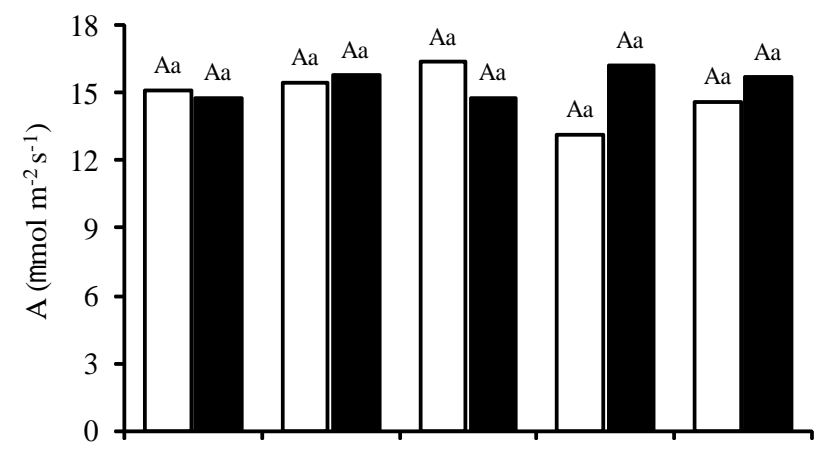

B.

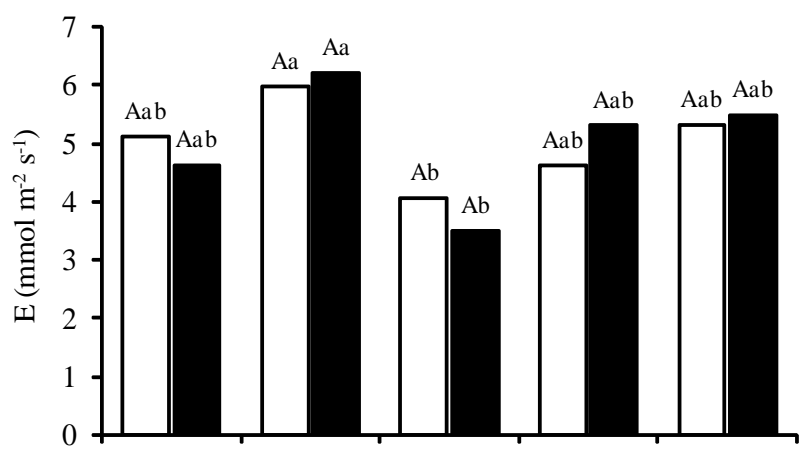

C.

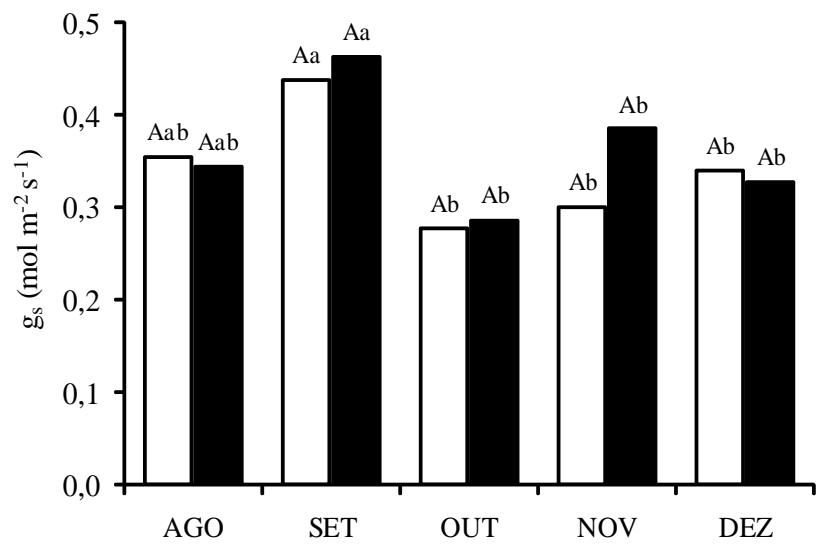

Valores (colunas) com a mesma letra maiúscula (tratamentos) ou minúscula (épocas) não diferem entre si pelo teste de Tukey $(P \leq 0,05)$

Figura 1. Fotossíntese líquida $(A)$, transpiração $(E)$ e condutância estomática $\left(g_{s}\right)$ em folhas de cajueiro anão precoce cultivado sob condições de sequeiro $(\square)$ e de irrigação ( $\square$ ) em função da época das determinações

hídricos e da interação sobre os valores de $\mathrm{E}$ e $\mathrm{g}_{s}$, embora os mesmos tenham sido influenciados pela época de avaliação. Cavalcanti et al. (2008), estudando a fisiologia do cajueiro anão precoce em ambiente protegido, observaram que o estresse hídrico não afetou o grau de abertura estomática, porém, foram observadas diferenças desta variável nas diversas fases fenológicas da cultura.

Os valores de E e g apresentaram estreita relação entre si, ao longo dos meses de avaliação, com um coeficiente de correlação de 0,83 , sendo que no mês de outubro se observaram menores valores, tanto na E quanto na $\mathrm{g}_{s}$ (Figura 1B e 1C) o que pode estar associado ao maior déficit de pressão de vapor da atmosfera que, neste mês, foi de $1,70 \mathrm{kPa}$ (Tabela 2) e que, por sua vez, provocou redução do potencial osmótico das plantas, no referido mês (Figura 2), mas a redução na $g_{s}$ não afetou a taxa fotossintética implicando em aumento na eficiência intrínseca do uso da água no período, o que pode comprovar a adaptação do cajueiro em regiões com baixa disponibilidade hídrica.

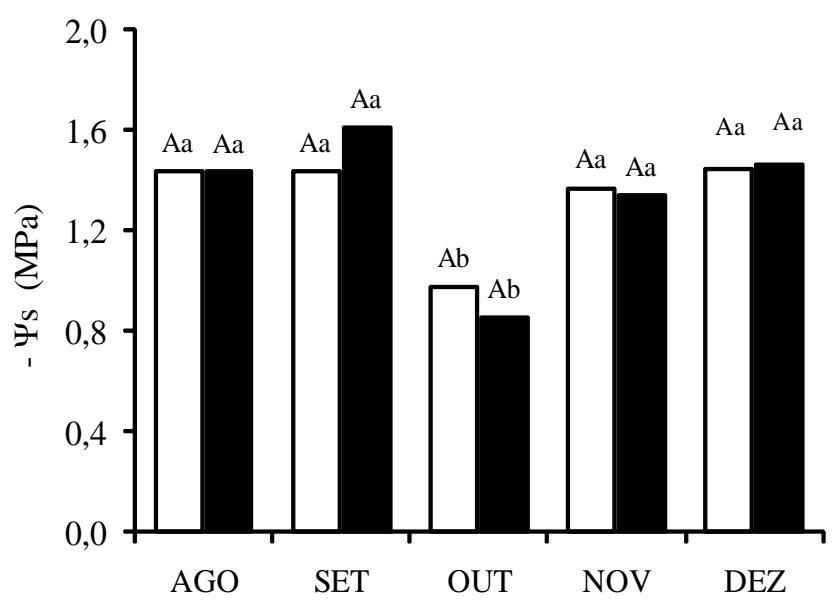

Valores (colunas) com a mesma letra maiúscula (tratamentos) ou minúscula (épocas) não diferem entre si pelo teste de Tukey $(P \leq 0,05)$

Figura 2. Potencial osmótico foliar $\left(\psi_{s}\right)$ em folhas de cajueiro anão precoce cultivado sob condições de sequeiro ( $\square$ ) e de irrigação ( $\mathbf{a}$ ) em função da época das determinações

Os resultados do estudo sobre as trocas gasosas sugerem que as plantas sob condições de sequeiro não sofreram estresse

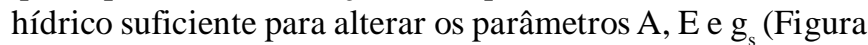
1), uma vez que não houve diferença no potencial osmótico entre as plantas irrigadas e as não irrigadas (Figura 2 e Tabela 4).

Resultados de trocas gasosas semelhantes aos do presente estudo, foram obtidos por Lima et al. (2010), em dois clones de cajueiro anão precoce adulto sob cultivo irrigado e não irrigado. Esses resultados divergem dos encontrados por Bezerra et al. (2007) ao observarem que a supressão da irrigação provocou reduções na A, E e $\mathrm{g}_{\mathrm{s}}$ em plantas de cajueiro com dois anos de idade. Segundo Kramer \& Boyer (1995), a restrição no uso da água pela diminuição na condutividade hidráulica associada ao aumento da resistência estomática contribui, em geral, para a diminuição na energia livre da água nos tecidos, provocando distúrbios metabólicos que poderão afetar o crescimento.

\section{Solutos orgânicos e inorgânicos}

Os teores foliares de $\mathrm{N}$-aminossolúveis e de prolina diferiram entre os regimes hídricos; apesar disto, o mesmo não ocorreu quando se analisaram os teores de carboidratos solúveis e dos íons $\mathrm{K}^{+}, \mathrm{Na}^{+}$e $\mathrm{Cl}^{-}$(Tabela 4). No entanto, quando se analisaram as épocas em que foram realizadas as determinações todos os parâmetros estudados diferiram mas a interação regime hídrico versus época não foi estatisticamente significativa, exceto no caso dos íons $\mathrm{Na}^{+}$e $\mathrm{Cl}^{-}$(Tabela 4).

Embora não tenham sido observadas diferenças estatísticas significativas nos teores de carboidratos solúveis entre os dois regimes hídricos, eles aumentaram progressivamente ao longo 
Tabela 4. Resumo da análise de variância para potencial osmótico ( $\left.\psi_{\mathrm{s}}\right)$, carboidrato solúvel ( $\mathrm{Cb}$. Sol.), $\mathrm{N}$-aminossolúvel ( $\mathrm{N}$-Am. Sol.), prolina (Pro), $\mathrm{Na}^{+}, \mathrm{Cl}^{-} \cdot \mathrm{K} \mathrm{K}^{+}$de folhas de cajueiro anão precoce cultivado sob condições de sequeiro e de irrigação

\begin{tabular}{lccccccc}
\hline \multirow{2}{*}{ Fonte de variação } & \multicolumn{7}{c}{ Quadrado médio } \\
\cline { 2 - 8 } & $\boldsymbol{\psi}_{\mathrm{s}}$ & $\mathbf{C b}$. Sol. & $\mathbf{N}-\mathbf{A m}$. Sol. & Pro & $\mathbf{N a}^{+}$ & $\mathbf{C l}^{-}$ & $\mathbf{K}^{+}$ \\
Regimes Hídricos (A) & $0,0007^{\text {ns }}$ & $4837,92^{\text {ns }}$ & $634,62^{\text {ns }}$ & $0,042^{* *}$ & $0,38^{\text {ns }}$ & $0,060^{\text {ns }}$ & $10,71^{\text {ns }}$ \\
Resíduo (A) & 0,037 & 4805,02 & 4,03 & 0,0008 & 4,064 & 1,238 & 1,328 \\
Época (B) & $0,46^{* *}$ & $143912,93^{* *}$ & $879,92^{* *}$ & $0,049^{* *}$ & $68,62^{* *}$ & $18,39 * *$ & $79,28^{* *}$ \\
Int. (A x B) & $0,023^{\text {ns }}$ & $5700,40^{\text {ns }}$ & $111,42^{\text {ns }}$ & $0,0008^{\text {ns }}$ & $5,97^{* *}$ & $0,90^{\text {ns }}$ & $0,570^{\text {ns }}$ \\
Resíduo (B) & 0,034 & 4298,15 & 52,44 & 0,0034 & 1,139 & 0,561 & 0,926 \\
CV\% (A) & 14,54 & 7,71 & 17,31 & 4,50 & 30,79 & 12,43 & 10,79 \\
CV\% (B) & 13,85 & 7,29 & 14,57 & 9,22 & 16,30 & 8,37 & 9,01 \\
\hline
\end{tabular}

$\left({ }^{*}\right)$ Significativo e ${ }^{(n s)}$ não significativo $(P \leq 0,05)$

do experimento, com diferença entre as épocas (Tabela 4 e Figura 3A).

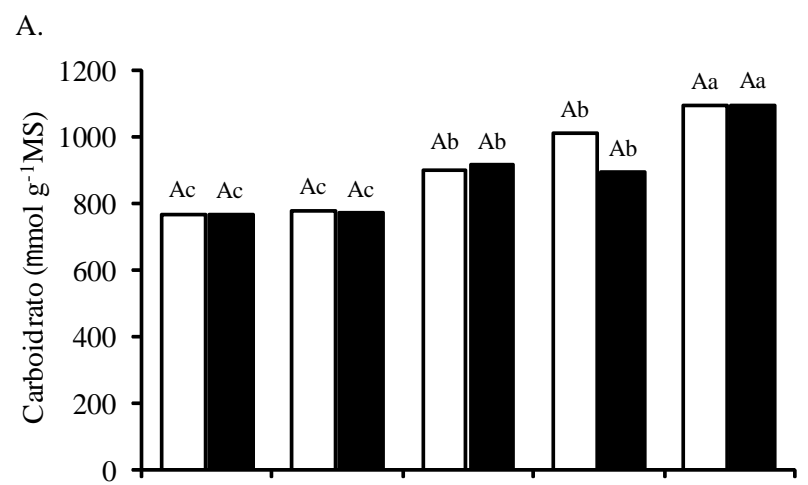

B.

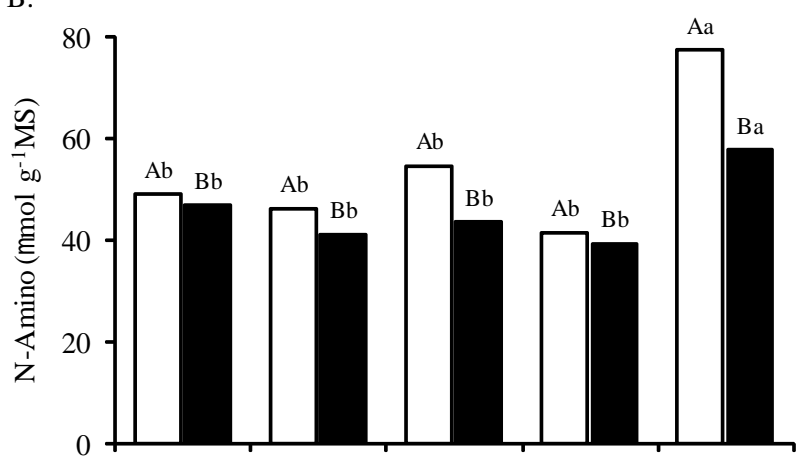

C.

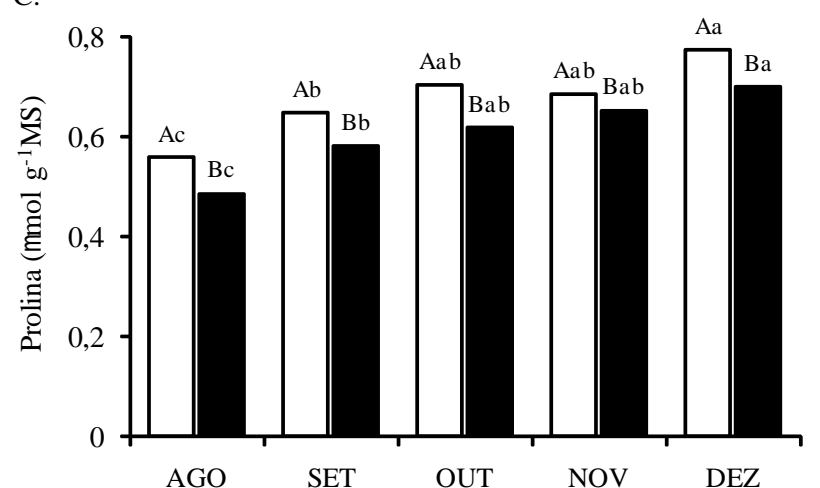

Valores (colunas) com a mesma letra maiúscula (tratamentos) ou minúscula (épocas) não diferem entre si pelo teste de Tukey $(P \leq 0,05)$

Figura 3. Teores de carboidratos solúveis $(A), N$ aminossolúveis $(B)$ e prolina $(C)$ em folhas de cajueiro anão precoce cultivado sob condição de sequeiro ( $\square$ ) e de irrigação $(\square)$ em função da época das determinações
Em dezembro, os teores desse soluto orgânico foram, em média, 42,7\% maiores que os observados em agosto, levandose em consideração os dados dos regimes hídricos com e sem irrigação. Por outro lado, os teores de $\mathrm{N}$-aminossolúveis e prolina foram influenciados pelos regimes hídricos e pelas épocas de avaliação não se verificando efeito da interação desses dois fatores.

De modo geral, as plantas não irrigadas apresentaram valores superiores, independente da época de coleta (Figura 3B e 3C). Comparando-se as épocas, verifica-se que no mês de dezembro as plantas não irrigadas tiveram um incremento nos teores de $\mathrm{N}$-aminossolúveis e prolina, de cerca de 57,7 e $38,4 \%$, respectivamente, quando comparados com os do mês de agosto. Os resultados sugerem que essas variáveis $(\mathrm{N}$ aminossolúveis e prolina) são extremamente sensíveis à variação do estado hídrico das plantas podendo ser utilizadas como sensores prévios de deficiência hídrica nas plantas.

A maioria dos organismos vegetais sintetiza solutos compatíveis em resposta ao estresse hídrico. Isto pode estar associado a vários fatores como, por exemplo: ao ajustamento osmótico, à manutenção da estabilidade funcional das enzimas e à proteção contra a desidratação (Bray et al., 2000); entretanto, no presente trabalho o aumento nos teores de solutos orgânicos parece estar mais associado à necessidade nutricional da planta, visto que esta ocorrência se deu no período reprodutivo, tanto nas plantas irrigadas quanto nas não irrigadas.

Quando se analisam as variações nos teores dos íons entre os dois regimes hídricos (Figura 4), observa-se que não houve diferença significativa para cloreto e potássio em nenhuma das datas de coleta (Figura 4B e 4C); entretanto, nas plantas não irrigadas o $\mathrm{Na}^{+}$teve um declínio no mês de outubro seguido de aumento no mês de novembro, em relação às irrigadas (Figura 4A).

Analisando o curso do experimento percebe-se que este íon se acumulou progressivamente nas folhas das plantas de ambos os regimes hídricos atingindo, em dezembro, um valor de cerca de $340 \%$, maior do que aquele observado no mês de agosto. Este incremento pode estar associado à modificação nos teores de sais, tanto da água de irrigação (poço artesiano) quanto na água do lençol freático, consequência da quase total ausência de precipitação média no período mencionado.

$\mathrm{O}$ acúmulo de $\mathrm{Cl}^{-}$nas folhas foi similar ao do $\mathrm{Na}^{+}$, tendo aumentado cerca de 42,2\% comparando-se os meses de agosto e dezembro nos dois tratamentos (Figura 4B). O acúmulo desses 
A.

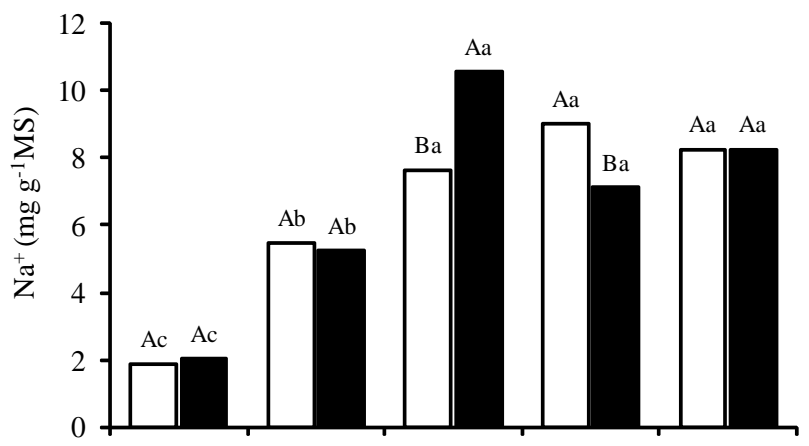

B.

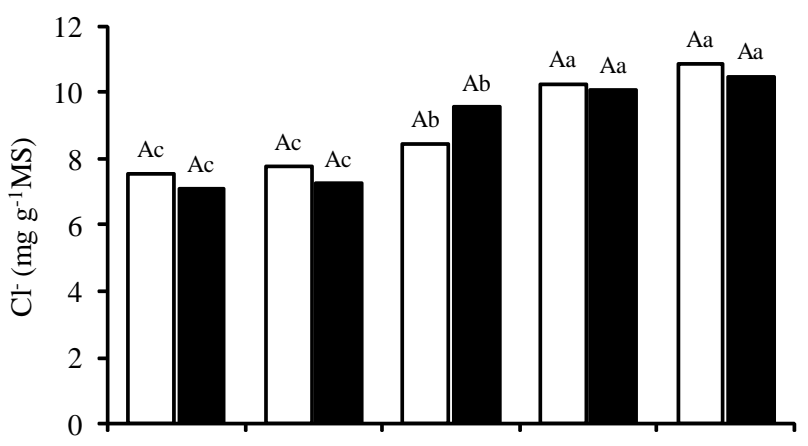

C.

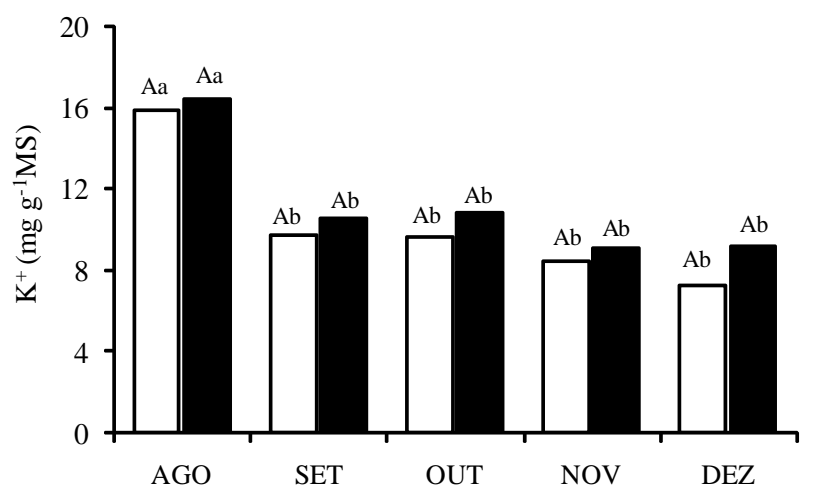

Valores (colunas) com a mesma letra maiúscula (tratamentos) ou minúscula (épocas) não diferem entre si pelo teste de Tukey $(\mathrm{P} \leq 0,05)$

Figura 4. Teores de $\mathrm{Na}^{+}(\mathrm{A}), \mathrm{Cl}^{-}(\mathrm{B}) \mathrm{e} \mathrm{K}^{+}(\mathrm{C})$ em folhas de cajueiro anão precoce cultivado sob condições de sequeiro $(\square)$ e de irrigação $(\square)$ em função da época das determinações

dois íons aparentemente não causou toxidez nas plantas estudadas, já que as mesmas não apresentaram sinais evidentes de estresse (redução do crescimento, queima das bordas das folhas) e não foi observado efeito sobre a taxa fotossintética (Figura 1A). Ao contrário do que ocorreu com os íons $\mathrm{Na}^{+} \mathrm{e} o$ $\mathrm{Cl}^{-}$, os teores de $\mathrm{K}^{+}$decresceram entre os meses de agosto e setembro mas se mantiveram estáveis ao longo do experimento (Figura 4C). Em média, os teores de $\mathrm{K}^{+} \mathrm{em}$ ambos os tratamentos, entre os meses de setembro a dezembro, foram $42,1 \%$ menores que aqueles observados em agosto.

$\mathrm{O}$ decréscimo no teor de $\mathrm{K}^{+}$a partir de setembro, período reprodutivo do cajueiro, pode ser explicado pela translocação deste nutriente para os órgãos em formação. De maneira geral, esta redução no teor de $\mathrm{K}^{+}$e o concomitante aumento no de
$\mathrm{Na}^{+}$, podem ser devidos a um processo de absorção competitivo (Grattan \& Grieve, 1999). Convém lembrar que o $\mathrm{Na}^{+}$pode também substituir o $\mathrm{K}^{+}$em algumas de suas funções (Taiz \& Zeiger, 2009). No presente trabalho o aumento nos teores foliares dos íons $\mathrm{Na}^{+} \mathrm{e} \mathrm{Cl}^{-}$não atingiu o limite de toxicidade nos cajueiros estudados, visto que não se observou influência negativa (redução do crescimento, queima das bordas das folhas) dos mesmos no desenvolvimento da planta, sugerindo que, ao invés de provocar efeito osmótico e tóxico, o aumento desses íons contribuiu para o funcionamento mais adequado das plantas estudadas.

\section{Produção}

Apesar de vários autores terem mostrado que plantios irrigados aumentam a produtividade das plantas de cajueiro (Oliveira, 2002), os resultados obtidos no presente estudo sinalizaram que a irrigação não aumentou a produção nem a produtividade de castanhas quando comparada com o plantio feito sob condições de sequeiro (Tabela 5), mesmo se utilizando a quantidade de água recomendada para cajueiros com a idade das plantas do presente estudo (Crisóstomo et al., 2001). Além disso, o número de castanhas por planta não diferiu estatisticamente nos dois tratamentos sendo observado, em média, o valor de 385 castanhas planta $^{-1}$.

Tabela 5. Produção e produtividade de castanhas de plantas de cajueiro anão precoce cultivado sob condições de sequeiro e de irrigação ${ }^{1}$

\begin{tabular}{ccc}
\hline $\begin{array}{c}\text { Condição } \\
\text { de cultivo }\end{array}$ & $\begin{array}{c}\text { Produção } \\
\text { (castanhas planta }\end{array}{ }^{-1}$ ) & $\begin{array}{c}\text { Produtividade } \\
\text { (kg ha }^{-1} \text { ) }\end{array}$ \\
Sequeiro & $369,4 \mathrm{a}$ & $612,80 \mathrm{a}$ \\
Irrigação & $399,6 \mathrm{a}$ & $670,83 \mathrm{a}$ \\
\hline
\end{tabular}

(1) Médias seguidas das mesmas letras em cada coluna, não diferem estatisticamente pelo teste de Tukey $(P \leq 0,05)$; dados representam valores médios das colheitas de agosto de 2006 a dezembro de 2007

Bezerra \& Miranda (1998) verificaram, trabalhando com o clone CCP-76 em regime de irrigação, que a manutenção da umidade no solo durante todo o ano, promoveu uma antecipação do início da produção, com a colheita sendo iniciada no mês de maio e se estendendo até dezembro, com pico de produção ocorrendo em setembro. Na Austrália observou-se um incremento de $20 \%$ na produção comercial ( $\mathrm{kg}$ castanhas planta $\left.{ }^{-1}\right)$ do cajueiro irrigado quando comparado com o não irrigado (Shcaper et al., 1996). Na Índia, avaliandose o efeito da aplicação de 30 litros de água planta ${ }^{-1}$ em intervalos que variaram de 10 a 60 dias, constatou-se que as plantas que foram irrigadas apresentaram melhorias no estabelecimento e na retenção do fruto, além de aumentarem a produção de castanha (Ghosh, 1995).

$O$ fato da irrigação não ter proporcionado aumento na produção de castanha das plantas, está coerente com a observação das respostas fisiológicas das plantas uma vez que as trocas gasosas, incluindo a fotossíntese das plantas, não diferiram entre os regimes hídricos aplicados (Tabela 3) e o teor de carboidratos solúveis, principal fonte de reserva energética das plantas, também não foi modificado em função da irrigação (Tabela 4). 


\section{CONCLUSÕES}

1. A ausência da irrigação não afetou os aspectos fisiológicos nem a produtividade de castanha das plantas, em relação às irrigadas.

2. Todas as variáveis estudadas, com exceção da fotossíntese, foram afetadas significativamente pela época de coleta dos dados, refletindo o estádio de desenvolvimento das plantas.

3. $\mathrm{O}$ aumento nos teores foliares de $\mathrm{Na}^{+} \mathrm{e} \mathrm{Cl}^{-}$ao longo do experimento não causou toxidade aparente nas plantas nem interferiu nas suas trocas gasosas.

\section{LITERATURA CITADA}

Bates, L. S.; Waldren, R. P.; Teare, I. D. Rapid determination of free proline for water-stress studies. Plant and Soil, v.39, p.205-207, 1973.

Bezerra, F. C.; Miranda, F. R. Efeito da densidade de plantio sobre o crescimento e a produção de cajueiro-anão-precoce irrigado. Fortaleza: Embrapa CNPAT, 1998. 4p.

Bezerra, M. A.; Lacerda, C. F. de; Gomes Filho, E.; Abreu, C. E. B.; Prisco, J. T. Physiology of cashew plants grown under adverse conditions. Brazilian Journal of Plant Physiology, v.19, p.449-461, 2007.

Bray, E. A.; Bailey-Serres, J.; Weretilnyk, E. Responses to abiotic stress. In: Buchanan, B.B.; Gruissem, W.; Jones, R.L. Biochemistry \& molecular biology of plants. 1.ed. Maryland: American Society of Plant Physiologist, 2000. p.1158-1203.

Carneiro, P. T.; Fernandes, P. D.; Gheyi, H. R.; Soares, F. A. L. Germinação e crescimento inicial de genótipos de cajueiro anão-precoce em condições de salinidade. Revista Brasileira de Engenharia Agrícola e Ambiental, v.6, p.199-206, 2002.

Cavalcanti, M. L. F.; Fernandes, P. D.; Gheyi, H. R.; Barros Júnior, G. Fisiologia do cajueiro anão precoce submetido à estresse hídrico em fases fenológica. Revista de Biologia e Ciências da Terra, v.8, p.42-53, 2008.

Crisóstomo, L. A; Santos, F. J. de S.; Oliveira, V. H.; Raij, B. van; Bernardi, A. C. de C.; Silva, C. A.; Soares, I. Cultivo do cajueiro anão precoce: Aspectos fitotécnicos com ênfase na adubação e na irrigação. Fortaleza: Embrapa Agroindústria Tropical, 2001. 20p. Circular Técnica, 08.

Dubois, M.; Gilles, K. A.; Hamilton, J. K.; Rebers, P. A.; Smith, F. Calorimetric method for determination of sugars and related substances. Analytical Chemistry, v.2, p.350-356, 1956.

FAO - Food and Agriculture Organization the Units Nations. Statistical Production. Crops Primary. Rome. In: FAOSTAT. FAO statistical data bases: Cantidad de producción. < http:/ /faostat.fao.org/site/291/default.aspx>. 03 Fev. 2009.

Gaines, T. P.; Parker, M. B.; Gascho, G. J. Automated determination of chlorides in soil and plant tissue by sodium nitrate. Agronomy Journal, v.76, p.371-374, 1984.
Ghosh, S. N. Studies on effect of watering during flowering and fruiting on yield of cashew. The Cashew, v.9, p.5-8, 1995.

Grattan, S. R.; Grieve, C. M. Salinity-mineral nutrient relations in horticultural crops. Scientia Horticulturae, v.78, p.127$157,1999$.

IBGE - Instituto Brasileiro de Geografia e Estatística. Levantamento Sistemático da Produção Agrícola - LSPA. <http://www.sidra.ibge.gov.br> 23 Out. 2008.

Kramer, P. J.; Boyer, J. S. Water relations of plants and soil. 2. ed. New York: Academic Press, 1995. 495p.

Lawlor, D. W.; Cornic, G. Photossynthetic carbon assimilation and associated metabolism in relation to water deficit in higher plants. Plant Cell and Environment, v.25, p.275-294, 2002.

Lima, M. de A.; Bezerra, M. A.; Gomes Filho, E.; Pinto, C. M.; Filho, J. E. Trocas gasosas em folhas de sol e sombreadas de cajueiro anão em diferentes regimes hídricos. Revista Ciência Agronômica, v.41, p.654-663, 2010.

Nogueira, R. J. M. C.; Moraes, J. A. P. V. de H.; Burity, A.; Bezerra Neto, E. Alterações na resistência à difusão de vapor das folhas e relações hídricas em aceroleiras submetidas a déficit de água. Revista Brasileira de Fisiologia Vegetal, v.13, p.75-87, 2001.

Oliveira, V. H. de. Cultivo do cajueiro anão precoce. Fortaleza: Embrapa Agroindústria Tropical, 2002a. 40p. Sistema de Produção, n.1.

Oliveira, V. H. de. Influência da irrigação na produção de pedúnculo e de castanha em cajueiro anão-precoce. Revista Brasileira de Fruticultura, v.24, p.717-720, 2002 b.

Oliveira, V. H. de. Cajucultura. Revista Brasileira de Fruticultura, v.30, p.1-3, 2008.

Oliveira, V. H. de.; Barros, L. M.; Lima, R. N. Influência da irrigação e do genótipo na produção de castanha em cajueiro anão-precoce. Pesquisa Agropecuária Brasileira, v.38, p.6166, 2003.

Schaper, H.; Chacko, E. K.; Blaikie, S. J. Effect of irrigation on leaf gas exchange and yield of cashew in northern Australia. Australian Journal of Agricultural Science, v.36, p.861-868, 1996.

Shinozaki, K.; Yamaguchi-Shinozaki, K. Gene networks involved in drought stress response and tolerance. Journal of Experimental Botany, v.58, p.221-227, 2007.

Silva, F. A. S.; Azevedo, C. A. V. de. Principal components analysis in the software Assistat-Statistical attendance. In: World Congress on Computers in Agriculture, 7, Orlando, Proceedings, Reno: American Society of Agricultural and Biological Engineers, 2009. CD-Rom

Souza, R. P.; Ribeiro, R. V.; Machado, E. C.; Oliveira, R. F.; Silveira, J. A. G. Photosynthetic responses of young cashew plants to varying environmental conditions. Pesquisa Agropecuária Brasileira, v.40, p.735-744, 2005.

Taiz, L.; Zeiger, E. Plant physiology. 4.ed. Sunderland: Sinauer Associates, Inc. Publishers, 2009. 848p.

Yemm, E.; Cocking, E. C. The determination of amino-acids with ninhydrin. Analyst, v.80, p.209-213, 1955. 